\title{
Oxide surface layer and solid-phase weldability of titanium alloys
}

\author{
R. Ya. Lutfullin ${ }^{\dagger}$, M. Kh. Mukhametrakhimov \\ †lutfullin.ramil@imsp.ru
}

Institute for Metals Superplasticity Problems, RAS, Ufa, 450001, Russia

It is known that the ultrafine-grained (UFG) structure in alloys is thermally unstable. An important task for the modern aviation engineering is to preserve the UFG structure in parts for responsible purposes after their production in order to maintain the high level of their mechanical properties. In particular, the solution to this task necessitates the reduction of the temperature of solid-phase bonding while ensuring the necessary quality of the permanent joint. It is known that along with the average grain size, the oxide surface layer can also significantly affect the solid-phase weldability of titanium alloys at low temperatures, but the latter has been extremely poorly studied. In this regard, the influence of an oxide film is considered for domestic two-phase titanium alloys VT6 (Ti-Al-V system) and VT8 (Ti-Al-Mo system), which differ in the main alloying element for the stabilization of the $\beta$-phase. As a result of the experiments, the absence of an oxide layer in the zone of solidphase connection of the ultrafine-grained (UFG) VT6 alloy after welding in vacuum at a reduced temperature of $600^{\circ} \mathrm{C}$ was metallographically revealed. This has a positive effect on the quality of welded samples according to the conducted mechanical tests. A continuous oxide layer was found in the solid-phase joint zone after welding at a temperature of $600^{\circ} \mathrm{C}$ for the UFG alloy VT8. The experimental results indicate that the UFG titanium alloy VT6, doped with relatively "mobile" vanadium, has the potential to reduce the lower temperature of solid-phase welding in vacuum by $50^{\circ} \mathrm{C}$ in comparison with the titanium alloy VT8.

Keywords: titanium alloys, weldability, oxide layer.

УДК: 621.791

\section{Оксидный поверхностный слой и твердофазная свариваемость титановых сплавов}

\author{
Лутфуллин Р. Я.†, Мухаметрахимов М.Х. \\ Институт проблем сверхпластичности металлов РАН, Уфа, 450001, Россия
}

Известно, что ультрамелкозернистая (УМЗ) структура в титановых сплавах является термически нестабильной. Актуальной задачей современного авиационного машиностроения является сохранение ультрамелкозернистости в титановых изделиях ответственного назначения после их изготовления для обеспечения высокого уровня механических свойств. Решение этой задачи, в частности, определяет необходимость снижения температуры твердофазной сварки при обеспечении необходимого уровня качества неразъемного соединения. Известно, что наряду со средним размером зерен, оксидный поверхностный слой также может существенно влиять при пониженных температурах на твердофазную свариваемость титановых сплавов, однако последний фактор чрезвычайно мало исследован. В этой связи для отечественных двухфазных титановых сплавов ВТ6 (система Ti-Al-V) и BT8 (система Ti-Al-Mo), отличающихся основным легирующим элементом для стабилизации $\beta$-фазы, рассмотрено влияние оксидной пленки. В результате проведения экспериментов металлографически выявлено отсутствие оксидного слоя в зоне твердофазного соединения ультрамелкозернистых образцов титанового сплава ВТ6 после сварки в вакууме при пониженной температуре, составляющей $600^{\circ} \mathrm{C}$. Это, согласно проведенным механическим испытаниям, положительно отражается на качестве сварных образцов. Для УМЗ титанового сплава ВТ8, легированного диффузионно «медленным» молибденом, после сварки при температуре $600^{\circ} \mathrm{C}$ в зоне твердофазного соединения обнаружен непрерывный оксидный слой. Результаты экспериментов свидетельствуют, что УМЗ титановый сплав ВТ6, легированный относительно «быстрым» ванадием, обладает потенциальной возможностью для снижения на $50^{\circ} \mathrm{C}$ нижней температуры твердофазной сварки в вакууме в сравнении с исследованным титановым сплавом ВТ8.

Ключевые слова: титановые сплавы, свариваемость, оксидный слой. 


\section{1. Введение}

Оксидный поверхностный слой является сдерживающим препятствием для формирования прочного твердофазного соединения (ТФС) при диффузионной сварке металлов и сплавов [1-4]. В этой связи решение актуального для авиационного машиностроения вопроса о возможности снижения температуры сварки в твердом состоянии, в частности титановых сплавов, невозможно без детального рассмотрения поведения при нагреве в вакууме оксидного слоя на поверхности соединяемых образцов.

Известно [5-7], что температуру сварки в твердом состоянии можно существенно понизить за счет уменьшения среднего размера зерен, используя эффект низкотемпературной сверхпластичности (СП). Однако влияние оксидного поверхностного слоя на твердофазную свариваемость и качество полученного неразъемного соединения остается до сих пор малоизученным, что сдерживает разработку перспективных технологий сварки давлением титановых сплавов.

Целью работы является выявление роли основного легирующего элемента, стабилизирующего $\beta$-фазу в титановых сплавах на возможность снижения температуры твердофазной сварки.

\section{2. Материал и методика исследования}

В качестве материалов для исследования выбраны двухфазные титановые сплавы ВТ6 и ВТ8 стандартного состава (ГОСТ 19807-91) легированные $\beta$-стабилизирующими элементами - ванадием и молибденом, соответственно, при относительно близком содержании в сплаве алюминия и других элементов (Табл. 1). Твердофазную сварку листовых заготовок осуществляли с использованием специализированной оснастки в вакуумной печи при температурах в интервале $550-750^{\circ} \mathrm{C}$ [8]. Исследовали титановые сплавы в мелкозернистом (М3) и ультрамелкозернистом (УМЗ) состояниях [8-10]. Качество твердофазного соединения (ТФС) оценивали по результатам микроструктурного анализа и механических испытаний по методике, изложенной в $[8,9]$. Структурные исследования проводили с использованием сканирующего электронного микроскопа «TESCAN MIRA3 LMU». Механические испытания ТФС на сдвиговую прочность $[9,10]$ проводили при комнатной температуре на испытательной машине фирмы «ИНСТРОН».

\section{3. Результаты и обсуждение}

Эксперименты по сварке в твердом состоянии ультрамелкозернистого (УМ3) титанового сплава ВТ6 при пониженных температурах показали [8], что имеется определенная зависимость твердофазной свариваемости от степени деформации. Например, качественное ТФС при температуре $750^{\circ} \mathrm{C}$ достигается уже при малой деформации, составляющей $5 \%$. Дальнейшее увеличение степени деформации сопровождается резким ростом зерен до микрокристаллических размеров [8-11], что отражается на механических свойствах сварных образцов. Влияние исходного размера зерен и эффекта структурной сверхпластичности (СП) являются определяющими в ускоренном формировании физического контакта $[12,13]$. Роль диффузии при этом также крайне важна, в частности на стадии объемного взаимодействия, но она практический не исследована для титановых сплавов при пониженных температурах, в том числе при проявлении низкотемпературной сверхпластичности (СП). В этой связи рассмотрим результаты механических испытаний на сдвиговую прочность твердофазных соединений, полученных в вакууме на листовых образцах сплава ВТ6 со средним размером зерен 0.2 мкм при температурах сварки в интервале $550-650^{\circ} \mathrm{C}$ (Табл. 2), когда диффузия в титановых сплавах крайне затруднена [14-16].

Анализ полученных результатов механических испытаний позволяет объяснить резкое, более, чем двухкратное снижение прочности ТФС сплава ВТ6, полученного при $550^{\circ} \mathrm{C}$, сохранением слоя оксидной пленки в зоне соединения (Рис. 1с). Действительно, в ходе сварочных экспериментов с образцами УМЗ сплава BT6, растворение и полное исчезновение оксидной пленки в зоне ТФС наблюдали только после повышении температуры сварки, начиная с $600^{\circ} \mathrm{C}$ (Рис. 1a, b).

Вероятно, структура оксидной пленки и диффузионные характеристики у сплавов, в частности у титановых [16], зависят от размера зерен, определяющих протяженность межзеренных и межфазных границ. На это указывают экспериментальные результаты, представленные в работе [3]. Авторами [17] было металлографически установлено исчезновение оксидной пленки в зоне ТФС при диффузионной сварке в вакууме микрокристал-

Табл. 2. Сдвиговая прочность твердофазных соединений при комнатной температуре.

Table 2. Shear strength of solid-phase joints (SPJ) at room temperature. Исходный размер зерен (мкм) сплава ВТ6; Прочность ТФС на температура сварки давлением, ${ }^{\circ} \mathrm{C} \quad$ сдвиг $\tau$, МПа

The initial grain size (microns) of the VT6 SPJ shear \begin{tabular}{l|l} 
alloy; pressure welding temperature, ${ }^{\circ} \mathrm{C}$ & strength $\tau, \mathrm{MPa}$ \\
\hline
\end{tabular}

\begin{tabular}{|c|c|}
\hline $0.2 ; 650$ & 599.1 \\
\hline $0.2 ; 600$ & 596.5 \\
\hline $0.2 ; 550$ & 221.0 \\
\hline
\end{tabular}

Табл. 1. Химический состав исследуемых титановых сплавов по ГОСТ 19807-91.

Table 1. Chemical composition of the investigated titanium alloys according to GOST 19807-91.

\begin{tabular}{|c|c|c|c|c|c|c|c|c|c|c|c|c|}
\hline \multirow{2}{*}{ Сплав / Alloy } & \multicolumn{12}{|c|}{ Содержание элементов, вес.\% / Alloying elements, wt.\% } \\
\hline & $\mathrm{Ti}$ & $\mathrm{Al}$ & $\mathrm{V}$ & Mo & $\mathrm{Zr}$ & $\mathrm{Si}$ & $\mathrm{Fe}$ & $\mathrm{O}$ & $\mathrm{H}$ & $\mathrm{N}$ & $\mathrm{C}$ & $\sum \Pi p$ \\
\hline BT6/ & Основа / Base & $5.3-6.8$ & $3.5-5.3$ & - & 0.30 & $\leq 0.10$ & $\leq 0.60$ & $\leq 0.20$ & $\leq 0.015$ & $\leq 0.05$ & $\leq 0.10$ & $\leq 0.3$ \\
\hline BT8 / VT8 & Основа / Base & $5.8-7.0$ & - & $2.8-3.8$ & 0.50 & $0.20-0.40$ & $\leq 0.30$ & $\leq 0.15$ & $\leq 0.015$ & $\leq 0.05$ & $\leq 0.10$ & $\leq 0.3$ \\
\hline
\end{tabular}




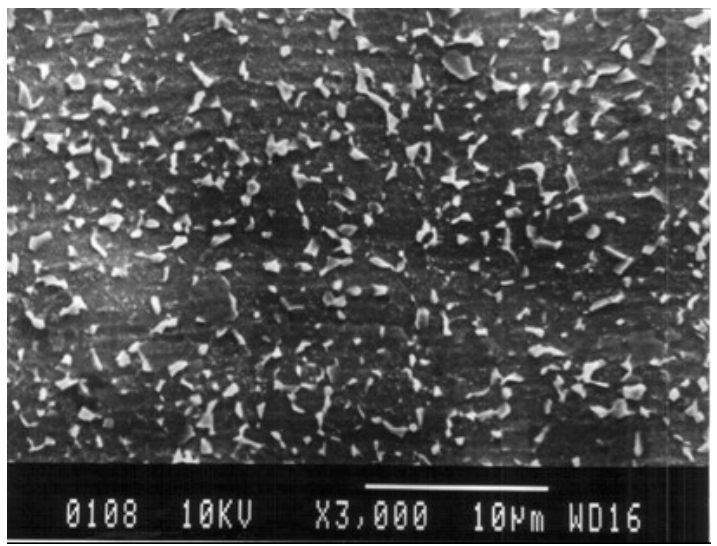

a

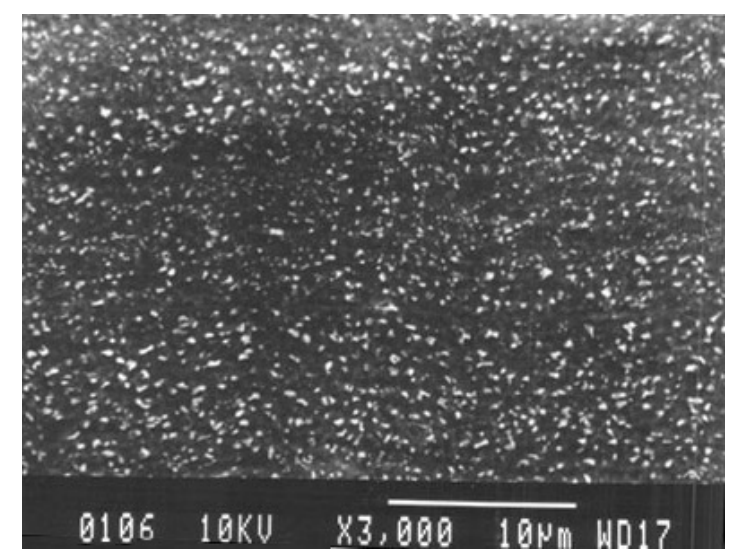

$\mathrm{b}$

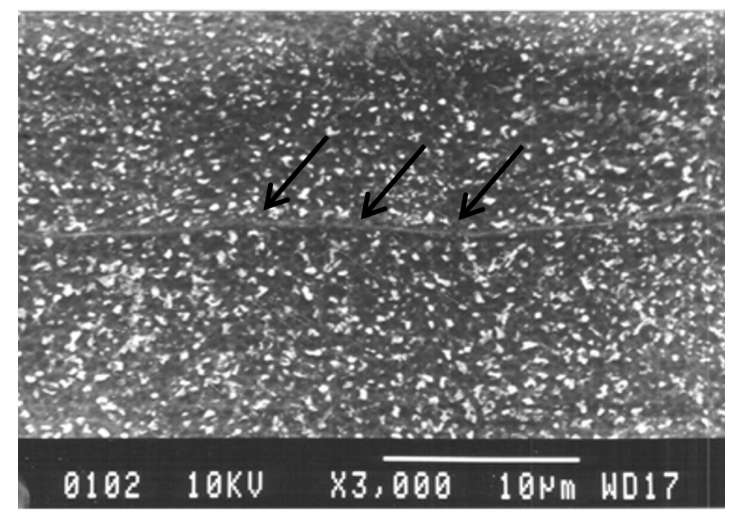

c

Рис. 1. Микроструктура зоны соединения образцов из УМЗ сплава ВТ6 после твердофазной сварки при температурах $650^{\circ} \mathrm{C}(\mathrm{a}), 600^{\circ} \mathrm{C}(\mathrm{b})$ и $550^{\circ} \mathrm{C}(\mathrm{c})$, стрелками указан оксидный слой.

Fig. 1. Micrograph of the joints out from UFG alloy VT6 after solid-phase bonding at temperatures of $650^{\circ} \mathrm{C}(\mathrm{a}), 600^{\circ} \mathrm{C}(\mathrm{b})$ and $550^{\circ} \mathrm{C}(\mathrm{c})$, the arrows indicate the oxide layer.

лического (размер зерен 3 мкм) сплава ВТ6 начиная с температуры $700^{\circ} \mathrm{C}$ и выше. При этом температура $700^{\circ} \mathrm{C}$ определена как пороговая, указывающая на нижний температурный предел твердофазной свариваемости, определяемый растворением оксидной пленки в исследуемом сплаве. С другой стороны, в работе [3] авторы впервые экспериментально показали, что в УМЗ (размер зерен не превышал 1 мкм) сплаве Ti-6Al-4V (ближайший зарубежный аналог сплава ВТ6), наблюдается ускоренная диффузия кислорода и образование поверхностного газонасыщенного альфированного слоя в сравнении с результатами экспериментов на традиционном микрокристаллическом сплаве $\mathrm{Ti}-6 \mathrm{Al}-4 \mathrm{~V}$ с размером зерен 8 мкм. Следовательно, логично предположить, что при нагреве в вакууме будет наблюдаться ускоренное растворение поверхностной оксидной пленки для сплава ВТ6 в УМ3 состоянии. Согласно [4], растворение поверхностной оксидной пленки на промышленном микрокристаллическом сплаве Ti-6Al-4V при нагреве в вакууме начинается с температуры выше $621^{\circ} \mathrm{C}$. Таким образом, анализ имеющихся экспериментальных результатов позволяет спрогнозировать, что в титановых сплавах типа ВТ6, легированных ванадием, уменьшение среднего размера зерен до УМЗ состояния, способствующих интенсифицированию диффузионных процессов [4], вполне вероятно снижение температуры растворения поверхностной оксидной пленки по крайней мере до $600^{\circ} \mathrm{C}$. При этом надо иметь ввиду, что легирующий элемент ванадий относится к относительно быстро диффундирующим элементам в титановом сплаве $[14,15]$. Легирование титанового сплава ВТ8 (система Ti-Al-Mo) диффузионно более «медленно» диффундирующим молибденом [14,15] затормаживает диффузионную активность и приводит к относительной стабилизации УМЗ структуры $[5,18,19]$ при умеренных температурах по сравнению с аналогичной структурой сплава ВТ6 $[19,20]$. Известные экспериментальные данные по росту зерен при нагреве [5,18-20], подтверждают приверженность к более высокой стабильности УМЗ структуры в сплаве ВТ8 в сравнении с УМЗ структурой сплава ВТ6 в интервале температур $550-750^{\circ} \mathrm{C}$. Известно [21], что рост зерен в УМЗ титановых сплавах определяется преимущественно диффузионной кинетикой. Таким образом, становятся понятными полученные экспериментальные результаты, свидетельствующие о сохранении металлографически видимой непрерывной оксидной пленки в зоне ТФС в сварных образцах из УМЗ сплава ВТ8, изготовленных в вакууме при температуре $600^{\circ} \mathrm{C}$ и исчезновения оксидного слоя в зоне ТФС для сварных образцов из УМЗ сплава ВТ6, полученных при идентичных условиях твердофазной сварки (температура, давление, время).

\section{4. Заключение}

Показано, что для УМЗ титановых сплавов ВТ6 и ВТ8 основной легирующий элемент, стабилизирующее $\beta$-фазу, может заметно влиять на растворимость оксидной пленки в процессе твердофазной сварки при пониженных температурах в вакууме. Выявленный эффект определяет для титанового сплава ВТ6 (система Ti-Al-V) дополнительную потенциальную возможность снижения нижней температуры для осуществления качественной твердофазной сварки приблизительно на $50^{\circ} \mathrm{C}$ в сравнении со сплавом ВТ8 (система Ti-Al-Mo). Максимально возможное снижение температуры твердофазной сварки является необходимым условием сохранения ультрамелкозернистой структуры в сварных образцах из титанового сплава ВТ6. 


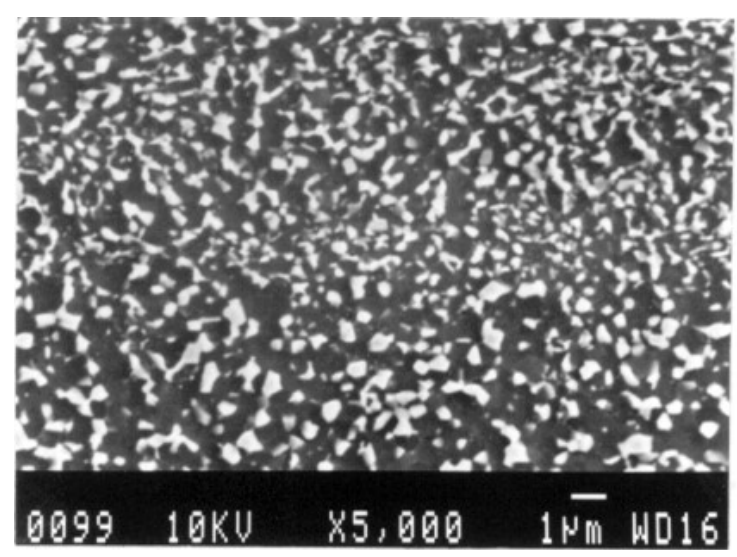

a

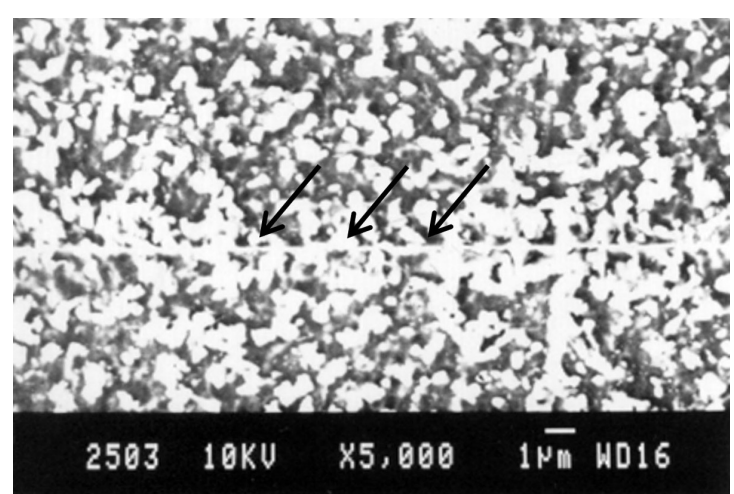

b

Рис. 2. Микроструктура зоны соединения образцов из УМЗ сплава ВТ8 после твердофазной сварки при температурах $650^{\circ} \mathrm{C}(\mathrm{a}), 600^{\circ} \mathrm{C}(\mathrm{b})$, стрелками указан оксидный слой.

Fig. 2. Micrograph of the joints out from UFG alloy VT8 after solidphase bonding at temperatures of $650^{\circ} \mathrm{C}(\mathrm{a}), 600^{\circ} \mathrm{C}(\mathrm{b})$, the arrows indicate the oxide layer.

Благодарности / Acknowledgments. Работа выполнялась в рамках государственной программы фундаментальных исстедований № АAAA-A17-117041310221-5. / The present work was accomplished according to the state assignment of IMSP RAS № AAAA-A17-117041310221-5.

\section{Литература/References}

1. Z.A. Munir. Supplement to the Welding Journal. December. 333s (1983).

2. E.S. Karakozov. Pressure welding of metals. Moscow, Machine-Building (1986) 280 p. (in Russian) [Э.С. Каракозов. Сварка металлов давлением. Москва. Машиностроение (1986) 280 с.]

3. F. Pitt, M. Ramulu. JMEPEG. 13 (6), 727 (2004). Crossref

4. F. C. Campbell. Manufacturing technology for aerospace structural materials. Amsterdam. Boston. Heidelberg. London, New York, Oxford, Paris, San Diego, San Francisco, Singapore, Sydney, Tokyo, Elsevier Ltd. (2006).

5. R. Ya. Lutfullin, O.A. Kaibyshev, R.V. Safiullin, O.R. Valiakhmetov, M.Kh. Mukhametrakhimov. Acta Metallurgica Sinica (English Letters). 13 (2), 561 (2000).

6. R. Ya. Lutfullin. Letters on Materials. 1 (1), 59 (2011). (in Russian) [Р. Я. Лутфуллин. Письма о материалах. 1 (1), 59 (2011).] rossref
7. M. Kh. Mukhametrakhimov. Letters on Materials. 2 (4), 249 (2012). (in Russian) [М. Х. Мухаметрахимов. Письма о материалах. 2 (4), 249 (2012).] Crossref

8. M. Kh. Mukhametrakhimov, R. Ya. Lutfullin. Proceedings of International Conference "Current status of Theory and Practice of Superplasticity in Materials". Ufa. Gilem (2000) p. 118. (in Russian) [M.X. Мухаметрахимов, Р.Я. Лутфуллин. Труды Международной научной конференции «Современное состояние теории и практики сверхпластичности материалов». Уфа, Гилем (2000) c. 118.]

9. R. Ya. Lutfullin, O.A. Kaibyshev, R.V. Safiullin, O.R. Valiakhmetov, M.Kh. Mukhametrahimov. Acta Metallurgica Sinica (English Letters). 13 (2), 561 (2000).

10. R. Ya. Lutfullin, O.A. Kaibyshev, O.R. Valiakhmetov, M.Kh. Mukhametrakhimov, R.V. Safiullin, R.R. Mulyukov. Advanced Materials. 4, 21 (2003). (in Russian) [Р.Я. Лутфуллин, О.А. Кайбышев, О.Р. Валиахметов, М.X. Мухаметрахимов, Р.В. Сафиуллин, Р.Р. Мулюков. Перспективные материалы. 4, 21 (2003).]

11. R. Ya. Lutfullin, M. Kh. Mukhametrakhimov. Metal Science and Heat Treatment. 2, 11 (2006). (in Russian) [Р. Я. Лутфуллин, М.Х. Мухаметрахимов. Металловедение и термическая обработка материалов. 2, 11 (2006).]

12. O. A. Kaibyshev, R. V. Safiullin, R.Y. Lutfullin, V.V. Astanin. J. Mater. Eng. Perform. 8 (2), 205 (1999). Crossref

13. R. Ya. Lutfullin. Letters on Materials. 1 (2), 88 (2011). (in Russian) [Р. Я. Лутфуллин. Письма о материалах. 1 (2), 88 (2011).] Crossref

14. U. Zwicker. Titan und Titanlegierungen. Moscow, Metallurgy (1979). (in Russian) [У. Цвиккер. Титан и его сплавы. Москва, Металлургия (1979) 512 с.]

15. G. Lütjering, J. C. Williams. Titanium, 2nd edition. Berlin, Heidelberg, New York, Springer (2007).

16. S.Z. Bokshtein, N.P. Zulina, O.V. Markovich. The Physics of Metals and Metallography. 4, 129 (1990). (in Russian) [С.3. Бокштейн, Н.П. Зюлина, О.В.Маркович. Физика металлов и металловедение. 4, 129 (1990).]

17. M. Kh. Mukhametrakhimov, R. Ya. Lutfullin. Fundamental'nye Problemy Sovremennogo Materialovedenia. 14 (4), 523 (2017). (in Russian) [M.X. Мухаметрахимов, P.Я. Лутфуллин. Фундаментальные проблемы современного материаловедения. 14 (4), 523 (2017).]

18. R. Ya. Lutfullin, O.A. Kaibyshev, R.V. Safiullin, O.R. Valiakhmetov, M.Kh. Mukhametrahimov, R.V. Safiullin, R.R. Mulyukov. Journal of Advanced Materials. 10 (4), 326 (2003).

19. G. A. Salishchev, O.R. Valiakhmetov, R.M. Galeyev, F.H. Froes. Materials Science Forum. 447-448, 441 (2004). Crossref

20. R. Ya. Lutfullin, M.Kh. Mukhametrakhimov. Metallovedenie I Termicheskaya Obrabotka Metallov. 2 (608), 11 (2006). (in Russian) [Р.Я. Лутфуллин, M.Х. Мухаметрахимов. Металловедение и термическая обработка металлов. 2 (608), 11 (2006).]

21. S.L. Semiatin, P.N. Fagin, J.F. Betten, A.P. Zane, A.K. Ghosh, G. A. Sargent. Metallurgical and Materials Transactions A. 41A, 499 (2010). $\underline{\text { Crossref }}$ 